\title{
Microstructure Changes Caused by Annealing of U-Pu-Zr Alloys
}

Dawn E. Janney and Bulent H. Sencer ${ }^{1}$

Idaho National Laboratory, Idaho Falls, ID 83415

${ }^{1}$ Formerly at Idaho National Laboratory

Corresponding author:

Dawn E. Janney

Idaho National Laboratory, Mail Stop 6188

Idaho Falls, ID 83415-6188

Phone: 208-533-7478

Fax: 208-533-7863

e-mail: dawn.janney@inl.gov

Postal address for Bulent Sencer is the same as for Dawn Janney. His email address is

bhsencer@gmail.com.

Manuscript to be considered for publication as a Short Communication in Journal of Nuclear Materials

This manuscript has been authored by Battelle Energy Alliance, LLC under Contract No. DE-AC07-05ID14517 with the U.S. Department of Energy. The United States Government retains and the publisher, by accepting the article for publication, acknowledges that the United States Government retains a nonexclusive, paid-up, irrevocable, world-wide license to publish or reproduce the published form of this manuscript, or allow others to do so, for United States Government purposes.

(C) 2016. This manuscript version is made available under the Elsevier user license http://www.elsevier.com/open-access/userlicense/1.0/ 


\section{ABSTRACT}

Thermally induced microstructural changes in five uranium-plutonium-zirconium alloys (38U-22Pu-40Zr, 49U-19Pu-32Zr, 33U-27Pu-40Zr, 19U-41Pu-40Zr, and 20U-12Pu-68Zr, compositions in at\%) were examined by comparing as-cast alloys with alloys that had been annealed at $500^{\circ} \mathrm{C}$ for 168 hours using scanning electron microscopy. All of the as-cast and annealed alloys had high-Zr inclusions not predicted from currently available phase diagrams. Microstructures in all alloys except U-12Pu-68Zr demonstrate increasing development of irregularly shaped polygons with high-actinide, low-Zr boundaries as a result of annealing.

\section{MAIN BODY}

The Fuel Cycle Research and Development (FCRD) project is examining ways to reduce the long-term radiotoxicity of nuclear waste by incorporating minor actinides into U-Pu-Zr alloys for transmutation to radionuclides with shorter half-lives. It is important to understand how phases and microstructures in fuels change as a result of conditions during service. Although these changes involve effects of both radiation and heating, it is useful to understand thermal and irradiation effects separately.

Thermally induced changes in five un-irradiated U-Pu-Zr alloys (Table 1) were investigated by comparing microstructures in as-cast and annealed samples. As-cast samples were prepared by arc-melting $\mathrm{U}, \mathrm{Pu}$, and $Z r$ feedstocks in appropriate proportions, then homogenizing the material by allowing it to cool, inverting it, and re-melting it at least twice. The alloys were melted a final time and drop-cast into quartz molds to produce cylinders $\sim 4 \mathrm{~mm}$ in diameter. Annealed samples were prepared by holding sections of the as-cast cylinders at $500{ }^{\circ} \mathrm{C}$ ( $775 \mathrm{~K}$ ) for seven days (168 hours) and allowing them to cool in the furnace for about one day.

Individual samples of the as-cast and annealed cylinders were prepared for analysis by scanning electron microscope (SEM) by cutting crosswise sections, embedding the sections in acrylic or epoxy, grinding and polishing by hand in an air-atmosphere glovebox with a water lubricant, and applying a thin layer of sputtered Pd to reduce sample charging. Sample surfaces were left somewhat rough to reduce personnel exposure during grinding and polishing.

Samples were examined using a JEOL JSM 7100F scanning electron microscope operating at a nominal voltage of $20 \mathrm{kV}$. X-ray maps showing qualitative distributions of individual elements were obtained using the $\mathrm{Zr} L \alpha, \cup \mathrm{M} \alpha$, and $\mathrm{Pu} M \beta X$-rays.

\section{Table 1. Alloy compositions}

\begin{tabular}{|l|l|l|}
\hline Nominal composition (at\%) & Nominal composition (wt\%) & Actual composition (wt\%) \\
\hline $38 \mathrm{U}-22 \mathrm{Pu}-40 \mathrm{Zr}$ & $50 \mathrm{U}-30 \mathrm{Pu}-20 \mathrm{Zr}$ & $49.6 \mathrm{U}-28.5 \mathrm{Pu}-19.8 \mathrm{Zr}$ \\
\hline $49 \mathrm{U}-19 \mathrm{Pu}-32 \mathrm{Zr}$ & $61 \mathrm{U}-24 \mathrm{Pu}-15 \mathrm{Zr}$ & $23.1 \mathrm{U}-59.3 \mathrm{Pu}-14.4 \mathrm{Zr}$ \\
\hline $33 \mathrm{U}-27 \mathrm{Pu}-40 \mathrm{Zr}$ & $43.5 \mathrm{U}-36.5 \mathrm{Pu}-20 \mathrm{Zr}$ & $41.8 \mathrm{U}-34.9 \mathrm{Pu}-20.3 \mathrm{Zr}$ \\
\hline $19 \mathrm{U}-41 \mathrm{Pu}-40 \mathrm{Zr}$ & $25 \mathrm{U}-55 \mathrm{Pu}-20 \mathrm{Zr}$ & $23.4 \mathrm{U}-33.9 \mathrm{Pu}-63.4 \mathrm{Zr}$ \\
\hline $20 \mathrm{U}-12 \mathrm{Pu}-68 \mathrm{Zr}$ & $35 \mathrm{U}-20 \mathrm{Pu}-45 \mathrm{Zr}$ & $33.9 \mathrm{U}-19.1 \mathrm{Pu}-43.3 \mathrm{Zr}$ \\
\hline
\end{tabular}


Figure 1 shows SEM images of the as-cast and annealed samples. Microstructures in each sample are qualitatively homogeneous on a scale of hundreds of micrometers to millimeters except near the outer edges of the samples, where the alloys were in contact with the molds.

High-Zr inclusions are common in all of the alloys. With the possible exception of U-12Pu-68Zr (at\%), none of the alloys has a high enough concentration of $\mathrm{Zr}$ to form $\alpha-\mathrm{Zr}$ according to published $\mathrm{U}-\mathrm{Pu}-\mathrm{Zr}$ phase diagrams [1]. High-Si inclusions and pores were also observed, but are less common than the high-Zr inclusions. No systematic differences in these features were observed in comparisons of as-cast and annealed samples.

As-cast microstructures in U-22Pu-40Zr, U-19Pu-30Zr, and U-27Pu-40Zr consist of a light-contrast matrix surrounding dark high-Zr inclusions (Figures $1 \mathrm{a}, 1 \mathrm{~b}$, and 1c). Subtle variations in contrast (particularly evident in Figure 1a) correspond to variations in concentrations of $U$ and $Z r$. Linear features are visible in some images (e.g., at arrows in Figures $1 \mathrm{~d}$ and $1 \mathrm{~g}$ ), and may be obscured in other areas by surface scratches. Small light and dark areas (possibly individual crystallites a few tens of $\mathrm{nm}$ across) are also visible in some images.

Annealed samples of these alloys show linear features bounding irregular polygons a few tens or hundreds of micrometers across (Figures 1b, 1c, 1e, 1f, 1h, and 1i). Details differ between samples: boundaries in U-22Pu-40Zr appear either as raised areas or as broad, flat areas with unusually light contrast (e.g., at arrows in Figure 1b), boundaries in U-19Pu-32Zr have parallel zones of material with darker and lighter contrast, and boundaries in U-27Pu-40Zr appear as areas of uniformly lighter contrast. X-ray maps (Figure 2) show that the boundaries in all three samples are depleted in Zr relative to the materials in the interiors of the polygons. Boundaries in annealed U-22Pu-40Zr have distinct high$\mathrm{U}$ and high-Pu regions.

The material in the interiors of the polygons in annealed U-22Pu-40Zr and U-19Pu-32Zr includes irregularly shaped light-contrast areas that appear similar to the polygonal boundaries (e.g., Figures $1 \mathrm{c}$ and 1f). The interiors of the polygons in annealed U-27Pu-40Zr contain elongated regions of lightcontrast material, which commonly intersect one another at approximately right angles.

As-cast microstructures in $\mathrm{U}-41 \mathrm{Pu}-40 \mathrm{Zr}$ consist of irregular hexagons a few tens of micrometers across (Figure 1j). Boundaries of the hexagons are light-contrast material, bracketed by darker-contrast stripes. The interiors of the hexagons are filled with elongated areas of light-contrast material, some of which terminate at the light-contrast material at the hexagonal boundaries. $\mathrm{X}$-ray maps indicate that the lightcontrast areas are enriched in $\mathrm{U}$, slightly depleted in $\mathrm{Pu}$, and strongly depleted in $\mathrm{Zr}$ relative to adjacent materials (Figure 2).

Microstructures in the annealed sample also consist of irregular polygons (Figures $1 \mathrm{k}$ and 1 l); however, the boundaries of the polygons appear thicker and the light-contrast areas inside the polygons are smaller. X-ray maps show that the material in the boundaries is significantly higher in $\mathrm{U}$ and lower in $\mathrm{Zr}$ than the material inside the polygons, and that the concentration of Pu is similar in both materials (Figure 2). 
Microstructures in the as-cast U-12Pu-68Zr alloy consist of lines of elongated high-Zr precipitates bounding irregularly shaped polygons of lighter-contrast material (Figure $1 \mathrm{~m}$ ). EDX maps show that there are no significant variations in concentrations of $U$ or $\mathrm{Pu}$ in the lighter-contrast material.

Microstructures in annealed U-12Pu-68Zr also show lines of high-Zr precipitates (Figures 1n and 10); however, it is subjectively less clear that the lines form polygonal boundaries. Based on the available SEM images, it appears that the high-Zr precipitates may be smaller in the annealed sample than in the as-cast one. However, further quantitative measurements are needed to confirm this assessment.

U-Pu-Zr phase diagrams suggest that the alloys considered here crystallized as ternary solid solutions between the body-centered-cubic (bcc) phases $\gamma-U, \varepsilon-P u$, and $\beta$-Zr, then transformed to lowertemperature phases during cooling [1]. An isothermal section at $500{ }^{\circ} \mathrm{C}$ (Figure 3 ) indicates that the equilibrium phases for the U-19Pu-32Zr, U-22Pu-40Zr, and U-27Pu-40Zr alloys are ternary solid solutions related to $\zeta-(\mathrm{U}, \mathrm{Pu})$ and $\delta-\mathrm{UZr}_{2}$. Although the temperatures of the reactions forming $\zeta-(\mathrm{U}, \mathrm{Pu})$ and $\delta-\mathrm{UZr}_{2}$ vary with composition, $\zeta-(\mathrm{U}, \mathrm{Pu})$ forms at a higher temperature than $\delta-\mathrm{UZr}_{2}$ in each alloy. More recent neutron-diffraction data confirms that the phases present in an alloy with 61.5 at\% $\mathrm{U}, 16$ at\% $\mathrm{Pu}$, and 22.5 at\% $\mathrm{Zr}$ alloy are $\zeta-(\mathrm{U}, \mathrm{Pu})$ and $\delta-\mathrm{UZr}_{2}$ at temperatures between 500 and $595{ }^{\circ} \mathrm{C}$, and that the $\zeta-(\mathrm{U}, \mathrm{Pu})$ forms at a higher temperature than the $\delta-U \mathrm{Ur}_{2}[2]$.

The SEM data presented here are consistent with identification of the lower-Zr matrix phase in annealed $\mathrm{U}-19 \mathrm{Pu}-32 \mathrm{Zr}$, U-22Pu-40Zr, and U-27Pu-40Zr alloys as $\zeta-(\mathrm{U}, \mathrm{Pu})$ and the higher-Zr matrix phase as $\delta-\mathrm{UZr}_{2}$.

The isothermal section is incomplete for high-Pu compositions but suggests that equilibrium phases for the $U-41 \mathrm{Pu}-40 \mathrm{Zr}$ alloy at $500{ }^{\circ} \mathrm{C}$ may include $\eta-(U, \mathrm{Pu})$ and $\delta-\mathrm{UZr}_{2}$ (Figure 3). Depictions of the reaction surface at which the bcc solid solution transforms to lower-temperature phases $[1,3]$ suggest that $\delta$ $(\mathrm{Pu}, \mathrm{Zr})$ may have been one of the first phases to form from the bcc solid solution. This implies that the low-Zr phase in the samples of $U-41 P u-40 Z r$ is $\eta-(U, P u)$ and the higher-Zr phase is $\delta$ - $(\mathrm{Pu}, \mathrm{Zr})$ or $\delta-U Z r_{2}$. If the high-Zr phase is $\delta-\mathrm{UZr}_{2}$, the sample composition and relatively homogeneous distribution of $\mathrm{Pu}$ shown by the $\mathrm{X}$-ray maps indicate that this phase may have a significantly higher concentration of $\mathrm{Pu}$ than is indicated by the isothermal section.

Figure 3 indicates that the equilibrium phase for the U-12Pu-68Zr alloy is $\delta-\mathrm{UZ}_{2}$. The apparent partial disappearance of the high-Zr inclusions during annealing suggests that they are not stable at $500{ }^{\circ} \mathrm{C}$.

Although the phase identifications presented here are tentative, the microstructures in all alloys except $\mathrm{U}-12 \mathrm{Pu}-68 \mathrm{Zr}$ demonstrate increasing development of irregularly shaped polygons bounded by high-U, low-Zr phases. Similar segregation in higher-temperature samples has been attributed to formation of $\zeta$ $(\mathrm{U}, \mathrm{Pu})$ at prior grain boundaries in the original bcc solid solution [4]. If this explanation for the polygonal boundaries in the samples considered here is correct, it demonstrates the importance of the early cooling histories of U-Pu-Zr alloys for predicting later development of microstructures in these alloys.

FIGURE CAPTIONS 
Figure 1. Back-scattered electron (BSE) SEM images of U-Pu-Zr alloys. Images in each row have the same composition, which is indicated in at\%. Images in the left column are from as-cast material; those in the middle and right columns are from annealed samples. Arrows show examples of polygonal boundaries. Images $\mathrm{a}, \mathrm{b}, \mathrm{j}, \mathrm{l}$, and $\mathrm{n}$ are from reference [5].

Figure 2. X-ray maps showing distributions of $\mathrm{U}, \mathrm{Pu}$, and $\mathrm{Zr}$ in as-cast and annealed samples of $\mathrm{U}-22 \mathrm{Pu}$ $40 \mathrm{Zr}$ and $\mathrm{U}-41 \mathrm{Pu}-40 \mathrm{Zr}$, including areas of Figures $1 \mathrm{~b}, 1 \mathrm{j}$, and $1 \mathrm{k}$. Contrast and brightness were adjusted separately for individual maps. Arrows in as-cast BSE image of U-22Pu-40Zr show surface contamination.

Figure $3.500{ }^{\circ} \mathrm{C}$ isothermal section proposed by $O^{\prime}$ Boyle and Dwight [1] (re-drawn after [6]). $\delta, \zeta$, and $\eta$ are ternary solid solutions corresponding to $\delta-\mathrm{UZr}_{2}, \zeta-(\mathrm{U}, \mathrm{Pu})$, and $\eta-(\mathrm{U}, \mathrm{Pu})$, respectively.

\section{ACKNOWLEDGMENTS}

The work described here was carried out in the Analytical Laboratory, Fuel Manufacturing Facility, and Electron Microscopy Laboratory at the Materials and Fuels Complex, Idaho National Laboratory. We would like to thank the facility management, health physics, and scheduling staff supporting these facilities. We would also like to thank the following individuals, without whose support this research could not have been performed: Ms. Cynthia Papesch, Mr. Bryan Forsmann, Mr. Jim Stuart, Mr. Spence Taylor, Dr. Robert D. Mariani, Dr. Thomas P. O’Holleran, and Dr. J. Rory Kennedy.

This research was supported by the U.S. Department of Energy, Office of Nuclear Energy (NE), under DOE Idaho Operations Office Contract DE-AC07-05ID14517.

\section{REFERENCES}

[1] D.R. O'Boyle, A.E. Dwight, The uranium-plutonium-zirconium ternary alloy system, in: W.N. Miner (Ed.) Plutonium 1970 and Other Actinides, Metallurgical Society of AIME, 1970, pp. 720-732.

[2] G.L. Hofman, L.C. Walters, Metallic fast reactor fuels, in: B.R.T. Frost, R.W. Cahn, P. Haasen, E.G. Kramer (Eds.) Materials Science and Technology, A Comprehensive Treatment, VCH Verlagsgesellschaft $\mathrm{mbH}, 1994$, pp. 1-43.

[3] P.A. Tucker, D.E. Etter, J.M. Gebhart, Phase study of uranium-plutonium-zirconium alloys, Transactions of the American Nuclear Society, 11 (1968) 99.

[4] Y.H. Sohn, M.A. Dayananda, G.L. Hofman, R.V. Strain, S.L. Hayes, Analysis of constituent redistribution in the gamma (bcc) U-Pu-Zr alloys under gradients of temperature and concentrations, Journal of Nuclear Materials, 279 (2000) 317-329.

[5] D.E. Janney, J.R. Kennedy, Microstructure changes during annealing of unirradiated U-Pu-Zr metal

fuels, Transactions of the American Nuclear Society, 103 (2010) 292-293.

[6] D.E. Janney, C.A. Papesch, S.C. Middlemas, FCRD Advanced Reactor (Transmutation) Fuels Handbook (Idaho National Laboratory Report INL/EXT-15-36520 revision 1), Idaho Falls, ID, 2016. 


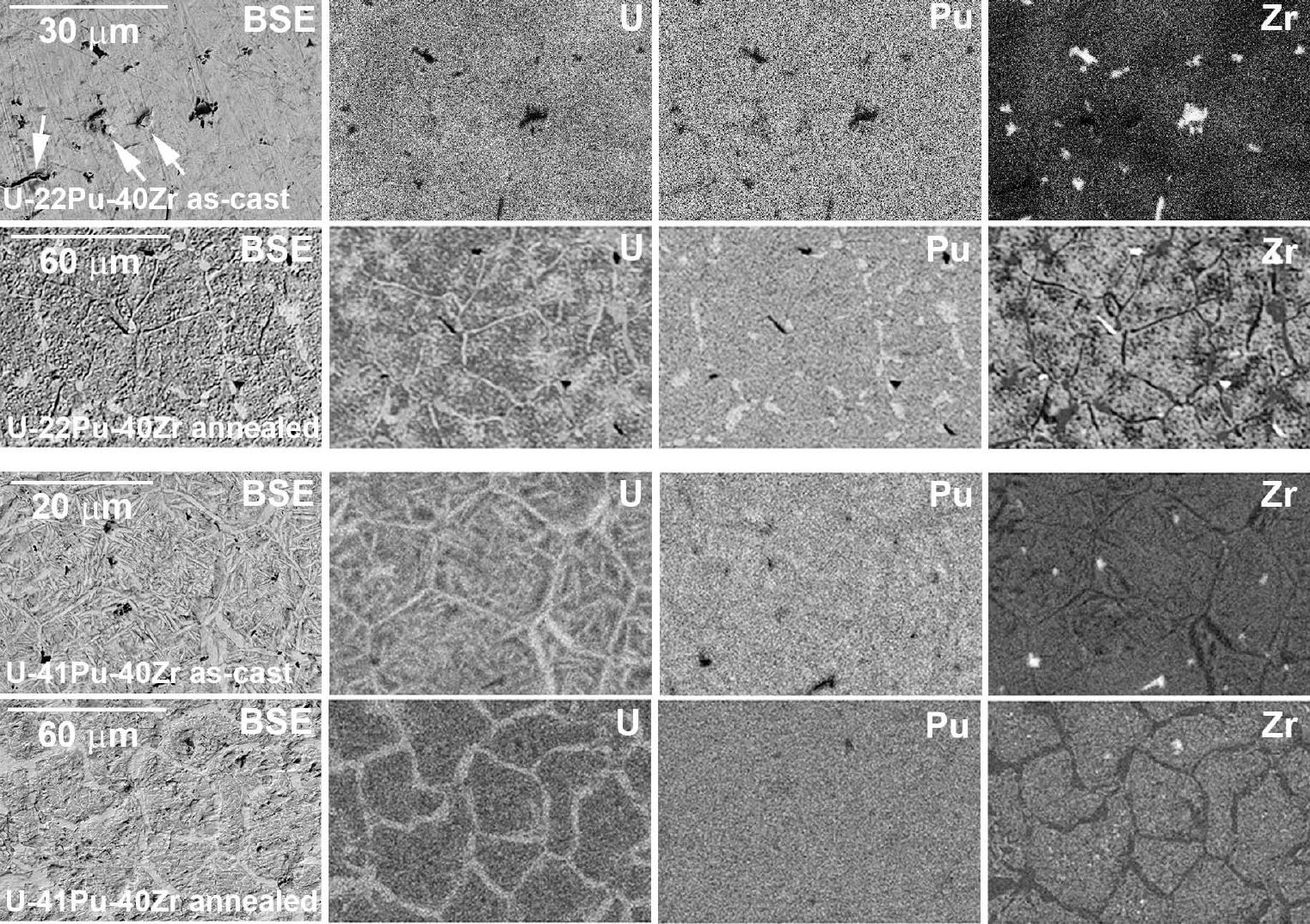




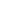

